\title{
Vaginal Reconstruction in Müllerian Agenesis with User- Friendly Indigenous Prosthetic Vaginal Dilators
}

\author{
${ }^{1} \mathrm{~K}$ Sangeetha, ${ }^{2} \mathrm{G}$ Usha Rani, ${ }^{3} \mathrm{O}$ Syamala, ${ }^{4}$ Rukshana, ${ }^{5}$ Pushpalatha
}

\begin{abstract}
Objective: Vaginal reconstruction in Müllerian agenesis through nonsurgical method, using serial vaginal dilators which were worn by the patients with the help of a T-shaped perineal bandage.
\end{abstract}

Materials and methods: Seven patients with Müllerian agenesis had attended the outpatient clinic between 2008 and 2013. The age of women ranged from 18 to 30 years. This clinical report describes the use of prosthesis, fabricated by a maxillofacial prosthodontist that enabled the patients to have custom made personalized vaginal dilators of increasing dimensions which they could wear with comfort with a tight perineal T-bandage.

Results: Seven women with Müllerian agenesis had consented for nonsurgical mode of vaginal reconstruction. Vagina was serially dilated with tailor made prosthesis worn using tight perineal T-bandage for a period of 3 to 4 months. Post dilatation average vaginal length was 11 to $13 \mathrm{~cm}$ which allowed introduction of Sims speculum with ease.

Conclusion: Nonsurgical vaginal dilatation using prosthetic vaginal dilators kept in place with tight perineal T-bandage is a well-accepted custom made and a successful technique in the creation of neovagina.

Keywords: Müllerian agenesis, Primary amenorrhea, Prosthetic vaginal dilator, Perineal T-bandage.

How to cite this article: Sangeetha K, Rani GU, Syamala O, Rukshana, Pushpalatha. Vaginal Reconstruction in Müllerian Agenesis with User-Friendly Indigenous Prosthetic Vaginal Dilators. J South Asian Feder Menopause Soc 2014;2(2):75-78.

\section{Source of support: Nil}

Conflict of interest: None

\section{INTRODUCTION}

Müllerian agenesis is also referred to as congenital absence of the uterus and vagina (CAUV) müllerian aplasia (MA), genital renal ear syndrome (GRES), and mayer-Rokitansky-Küster-Hauser syndrome (MRKH).

\footnotetext{
${ }^{1}$ Postgraduate Student, ${ }^{2,5}$ Professor, ${ }^{3}$ Associate Professor

${ }^{4}$ Assistant Professor

${ }^{1-5}$ Department of Obstetrics and Gynecology, Sri Ramachandra University, Chennai, Tamil Nadu, India
}

Corresponding Author: G Usha Rani, Professor, Department of Obstetrics and Gynecology, Sri Ramachandra University, Porur Chennai, Tamil Nadu, India, Phone: +91-9841067790, e-mail: usha_jagan2003@yahoo.com
This syndrome is subdivided into two types: Type I (isolated) and Type II or MURCS association (Müllerian duct aplasia, renal dysplasia and cervical somite anomalies). ${ }^{1}$ MRKH or Mayer-Rokitansky-Küster-Hauser Syndrome was named after August Franz Joseph Karl Mayer, Carl Freiherr von Rokitansky, Hermann Küster, and GA Hauser. It is a congenital malformation in women characterized by a failure of the Müllerian ducts to develop, resulting in a missing uterus and variable malformations of the vagina. Müllerian agenesis has been considered as a sporadic anomaly, ${ }^{2}$ but the increase in familial cases now supports the hypothesis of a genetic cause. It is transmitted as an autosomal dominant trait with incomplete penetrance and variable expressivity. It is reported to occur as a case in 4000 to 10,000 live female births. It is the second most common cause of primary amenorrhea. ${ }^{2}$ Generally, patients with Müllerian agenesis present with primary amenorrhea, with 46 XX karyotype and normal functioning ovaries. The management of vaginal agenesis aims at the creation of functional vagina for successful sexual life and issue of fertility.

Nonsurgical management for vaginal reconstruction in Müllerian agenesis was described by Frank in 1938 and Ingram in 1981. Both methods used dilators which were fixed on bicycle seats. The women had to sit on them for specified periods of time.

We describe the creation of functional vagina in seven women with Müllerian agenesis. One of the seven women had oocyte retrieval, IVF, and embryo transfer in a surrogate. The method used was based on the principles of prosthetic dilators of Frank and Ingram. The dilators were kept in place by the patient with the help of tight perineal T-bandage. The patients were able to wear it while they were ambulant. This aspect of mobility was easily accepted by the women. The compliance was very good. The duration of use of the dilators was 8 to 10 hours per day. The time taken for the creation of a functional vagina varied from 3 to 4 months, depending on the number of hours it was worn per day.

\section{MATERIALS AND METHODS}

Seven patients with Müllerian agenesis had attended the outpatient clinic between 2008 and 2013. The age of the patients ranged from 18 to 30 years. Four of them were 
unmarried, two were engaged and one was married. All of them had an established diagnosis of Müllerian agenesis. The use of a vaginal dilator is a nonsurgical method of management for patients with complete Müllerian agenesis. The department of maxillofacial prosthodontist in our hospital played an important role in the nonsurgical management, as the fabrication of the vaginal dilator is done by the prosthodontist (Figs 1A and B). During the first session the patient was given a vaginal dilator measuring $2.5 \mathrm{~cm}$ in length and $1 \mathrm{~cm}$ in width with a round wide base. The patient was advised to use the prosthesis for duration of 8 to 10 hours a day for a period of 1 month. Retention and pressure was applied and maintained by the use of tight perineal T-bandage (Fig. 2). She was also instructed to maintain good personal hygiene and of that of the stent. A thorough wash under fast running water and cleansing with a mild detergent was advised before and after usage to prevent fungal

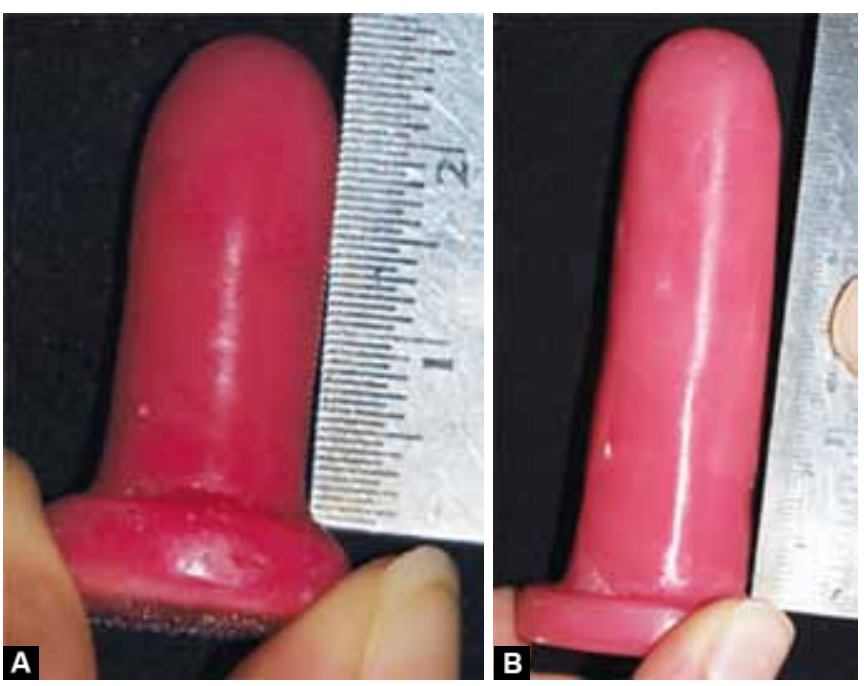

Figs $1 \mathrm{~A}$ and $\mathrm{B}$ : Vaginal dilator

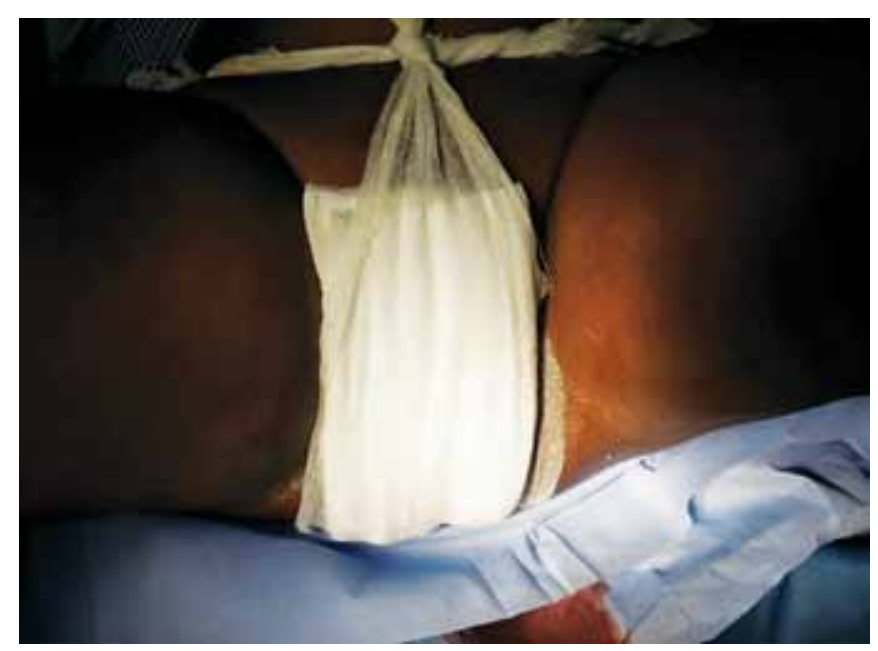

Fig. 2: Tight perineal T-bandage applied to the patient growth. On reviewing after a period of 1 month, the patient was found to be using the dilator with comfort. Sequentially, the measurements were increased to (length $\times$ width) $3.5 \times 1.5 \mathrm{~cm}, 4 \times 1.5 \mathrm{~cm}$ and finally $7.5 \times 2 \mathrm{~cm}$ over a period of 3 months. The initial prosthesis was relined to achieve the new measurement. To achieve this, the prosthesis was roughened by the use of sand paper, then covered by wax till the desired measurements of $3.5 \times$ $1.5 \mathrm{~cm}$ were achieved, then it was flasked, dewaxed and processed. The final relined prosthesis was then trimmed, finished and highly polished. As per the treatment plan, the patient was reviewed after a period of 1 month and given a newly relined prosthesis measuring $4 \times 1.5 \mathrm{~cm}$. After a total of 4 months, the patient was given a final prosthesis measuring $7.5 \times 2 \mathrm{~cm}$ (Fig. 2). This was used for another month. On reviewing, the patient was found to have a vaginal opening measuring 11 to $13 \mathrm{~cm}$.

\section{RESULTS}

All seven patients were well motivated and supported by their mother. Two of the patients who were engaged and one patient who was married used the mold very regularly with good results. Those who were not married needed extracounselling for proper usage. There were no adverse effects observed with usage of dilators. At the end of 3 to 4 months of use the mean vaginal length achieved 11 to $13 \mathrm{~cm}$. vagina was capacious enough to allow the insertion of sims speculum (Fig. 3). Lining of vaginal was normal vaginal epithelium. One of these patients later underwent transvaginal oocyte retrieval IVF, transfer of embroys in surrogate. Oocyte retrieval was done comfortably pervaginally in this patient. Patients were encouraged to continue use of vaginal dilators for shorter duration of period till active sexual life is initiated.

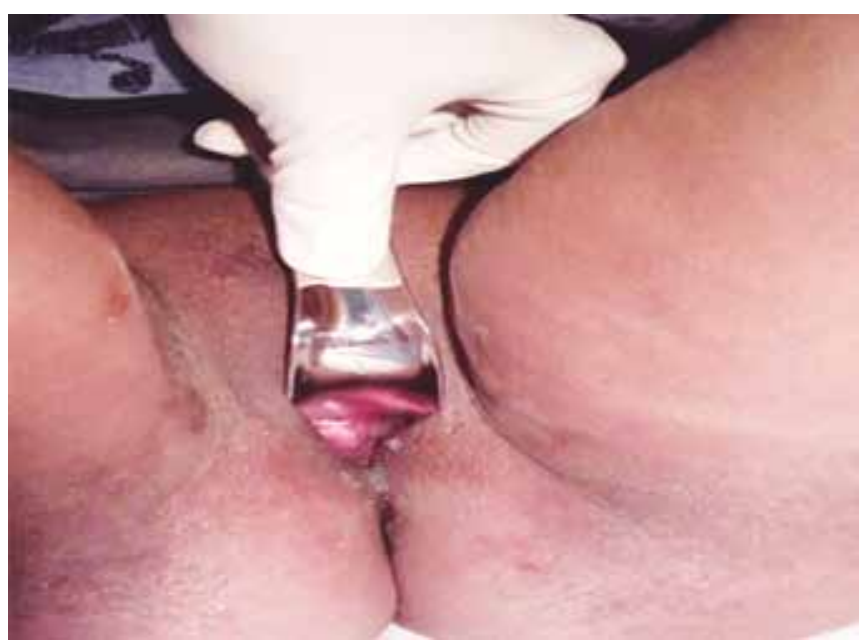

Fig. 3: Vagina of the patient is capacious enough to allow Sims' speculum 


\section{DISCUSSION}

There are many surgical and nonsurgical techniques for neovaginal creation whereas adoption and assisted reproduction satisfies the issue of reproduction. Nonsurgical treatment is the first choice as stated by the ACOG committee.

Progressive perineal dilatation was first described in 1832 by Amussat and modified by Frank in $1938 .{ }^{3}$ The principle involved is that dilator is placed at the vaginal dimple and pressure is applied. Vaginal tissues become softer and more pliable over a period of time gradually developing in the region previously underdeveloped. The success of the nonsurgical technique of dilatation is strong motivation of the patient and family members. All the seven patients were strongly motivated by their mother who gave them emotional support during the period. The success rate further increased when patient had regular sexual intercourse in addition. ${ }^{4}$ Serial dilators were used for dilatation. Timing of treatment depends on when the patient is physically and emotionally mature. ${ }^{5}$

Frank's (1938) handheld technique use pyrex dilators had technical limitations, such as hand fatigue and uncomfortable positions. ${ }^{3,6}$ Ingram's method (1981) is a passive method where patient sits on a bicycle seat equipped with a dilator. ${ }^{6}$ The difficulties faced were fabrication of bicycle in busy outpatient clinic. ${ }^{7}$ MeeHwaLee used an ordinary chair instead of bicycle seat. ${ }^{8}$

Here, we report a technique of modification of Frank's technique using acrylic resin. The dilators were used with tight perineal T-bandage which applied firm and continuous constant pressure to the vaginal tissue without the use of patients hand. Advantages are that these dilators are passive and do not require any extra effort from the patient, can be used during day to day activities. The duration of use was 8 to 10 hours per day. The time taken for creation of functional vagina varies from 3 to 4 months depending on the number of hours worn per day.

Prosthetic vaginal dilators made with acrylic resin tend to be heavier than those made with silicon material. Acrylic resin is a harder material as compared to silicon. Silicon though a softer material due to its flexible property over acrylic resin it may cause failure to achieve the desired size of the vagina. The fabrication of an acrylic resin dilator is less tedious as it also permits relining, hence reduces expense. It is also easy to clean and maintain allowing better hygiene. ${ }^{9}$

Various surgical techniques have been proposed for creation of neovagina including perineal vaginal dilatation with inlay skin flap (McIndoe), bowel vaginoplasty (Baldwin), peritoneal vaginoplasty (Davydov), and local cutaneous flap (Williams operation), and myocutaneous flap, laparoscopic Vecchietti operation. Complication of any surgical technique for neovagina are inadvertent rectal and bladder perforation, vesicovagina fistula. Sigmoid colpoplasty can result in excessive, malodorous vaginal mucus or neovaginal prolapse, bowel obstruction, leakage of intestinal anastomosis, necrotizing fasciitis, vaginal prolapse. Graft contraction, keloid scar formation in cases with skin grafting occur, leading to distortion of pelvic anatomy and increases the risk of scarring with resultant dyspareunia and apareunia. ${ }^{10}$

Furthermore, a large percent of patients who undergo surgical neovagina creation, subsequently require dilatation therapy including up to $73 \%$ where skin graft has been used. ${ }^{11}$

Surgical methods of neovaginal creation make oocyte retrieval more difficult than graded perineal dilatation. ${ }^{12}$ A high lateral placement of ovaries has been described in patients with Müllerian agenesis who undergo oocyte retrieval for gestational carrier treatment. The high lateral ovarian position is combined with a relative in elastic neovagina making transvaginal ultrasound-guided oocyte retrieval difficult. Laparoscopic oocyte retrieval may, therefore, be frequently required in patients with Müllerian agenesis. ${ }^{13}$ However, one of our patients underwent transvaginal oocyte retrieval due to the pliable and good spacious vagina created after regular dilatation.

Surgical technique is only used for those patients with failure of nonsurgical technique due to lack of motivation. ${ }^{14}$

Nonsurgical dilatation allows vagina to be created from normal vaginal skin giving it normal characteristics.

The primary endpoint in these patients should be creating a vagina that is satisfactory for sexual intercourse and provides adequate cosmesis of the external genitalia, while minimising short-term and long-term morbidity. ${ }^{10}$

We have shown that vaginal dilatation had significantly increased vaginal length in patients with Müllerian agenesis in a shorter period by encouraging patients in using passive techniques, user-friendly indigenous dilators with tight perineal T-bandage. These patients also achieve comfortable sexual activity.

\section{CONCLUSION}

Nonsurgical dilatation is the first and the most effective and an ideal passive method in the creation of functional neovagina. Nonexpensive non-time consuming, low maintenance often improves the compliance of the technique. In our endeavor to make easily accessible, costeffective daily wear method for vaginal reconstruction, we presented seven cases with successful outcome with vaginal dilatation using tight perineal T-bandage. 


\section{ACKNOWLEDGMENTS}

We would like to personally thank Paturu Rasmi, Reader, Prof TV Padmanabhan, Professor and Head, Department of Prosthodontics, Sri Ramachandra University, Porur, Chennai, India, for their untiring support.

\section{REFERENCES}

1. Guerrier D, Karine M. Mayer-Rokitansky-Küster-Hauser (MRKH) syndrome. Orphanet Journal of Rare Diseases 2007; 2:13.

2. Pandey B, Hamdi IM. Mayer-Rokitansky-Küster-Hauser syndrome of Müllerian agenesis. Saudi Med J 2003;24(5):1152.

3. Frank TR. The formation of an artificial vagina without operation. Am J Obstet Gynaecol 1938;35:1053.

4. Lappohn RE. Congenital absence of vagina results of conservative treatment. Eur J Obstet Gynaecol Reprod Biol 1995;59(2):183-186.

5. Alderson J, ed. A nonsurgical approach to the treatment of vaginal agenesis. Paediatric and adolescent gynaecology. Cambridge University Press; 2004.

6. Ingram JM. The bicycle seat stool in the treatment of vaginal agenesis and stenosis: a preliminary report. Am J Obstet Gynaecol 1981;140(8):867-873.
7. Roberts CP, Haber MJ, Rock JA. Vaginal creation for mullerian agenesis. Am J Obstet Gynaecol 2001;185(6):1349-1352.

8. Mee-HwaLee. Nonsurgical treatment of vaginal agenesis using simplified method of Ingram's method Yonsei. Med J 2006 Dec 31;47(6):892-895.

9. Rasmi P, Padmanabhan T, Mohammed K, Maheswari M, Swarup S. Prosthetic vaginal dilator-a case report. International J Obstet Gynaecol 2010;15(1).

10. Gargoll PC. Should Progressive perineal dilatation be considered first line therapy for vaginal agenesis? J Urology 2009 Oct;182(4 Suppl):1882-1891.

11. Klingele CJ, Gebhart JB, Croak AJ, et al. McIndoe procedure for vaginal agenesis: long term outcome and effect on quality of life. Am J Obstet Gynaecol 2003;189(6):1569.

12. Robson S, Oliver GD. Management of vaginal agenesis: review of 10 years practice at a tertiary referral centre. Aust NZJ Obstet Gynaecol 2000;40(4):430-433.

13. Wood EG, Batzer FR, Corson SL. Ovarian response to gonadotrophins, optimal method for oocyte retrieval and pregnancy outcome in patients with vaginal agenesis. Human Reprod 1999;14(5):1178-1181.

14. Foley, Sallie, George W Morley. Care and counselling of the patient with Vaginal agenesis. The Female Patient 1992 Oct 17:73-80.

15. Lloyd J, Crunch NS, Minto XL, et al. Female genital appearance: 'normality' unfolds. BJOG 2005;112(5):643-646. 